\title{
Status Quo, Problems and Counter Measures for the Sports Public Service System of Suzhou
}

\author{
Dongdong Bao, Duanyang Ren, Zhangzhi Ge \\ School of Public Affairs, University of Science and Technology of China, Hefei, China \\ Email: rdy@mail.ustc.edu.cn, 897063685@qq.com
}

Received 7 August 2014; revised 10 September 2014; accepted 8 October 2014

Copyright (C) 2014 by authors and Scientific Research Publishing Inc.

This work is licensed under the Creative Commons Attribution International License (CC BY).

http://creativecommons.org/licenses/by/4.0/

(c) (i)

\begin{abstract}
We analyze the status quo of Suzhou sports public service system by the method of literature, questionnaire, interview etc. Such countermeasures are proposed as the target of perfecting the supporting and guaranteeing system, involving improve the sports facilities, increase public investment, expand the supply of sports public services channels, construct the performance evaluation system for sports public service and so on, as the development of countermeasures.
\end{abstract}

\section{Keywords}

\section{Sports Public Service, Suzhou City, Countermeasures}

\section{Introduction}

With the development of social and economy, sports undertakings becoming an important part of government's public service items, and also has got unprecedented development. Under the influence of new public management theory and new public service theory, the governments gradually shift to "service-oriented". In these efforts, constructing sports public service system is a top priority [1]. Sports undertakings play an important role in public service, which is one of the top five public utilities of China. Providing public sports services is the focus and essence of mass sports work of our country in current and coming period. The Chinese government has clearly put forward that the construction of the public service system as a basic task of building a serviceoriented government in the new era. Besides, in the "12th five-year plan", the government further emphasizes the leading role of itself, strengthen the function of social management and public service, to build a serviceoriented government and improve the capability of service and management. Thus it is urgent to build and develop sports public service system. Parts of the public sectors have begun to explore the issues in their own 
fields which related to the construction of sports public service function. However, with the economy development, the development process of sports public service is relatively slow, especially people have more demand for public service, but the service offered by the government is relatively insufficient, with low quality [2].

Sports public service is important for maintaining the social justice. During the social transition period, strengthening the government function of sports public service and improving the service of sports could contribute to the social development healthy. It has strong strategic significance. Therefore, we strive to study the construction and development of sports public service as well as the role of government during the function transformation period. Due to the fact that the local government is the main provider of sports public service, considering the region diversity and develop unbalance, so we choose Suzhou city as the object of study. This is because, Suzhou has developed economy, and it has ability to provide good quality services. Second, the sports undertakings develop well and it has a certain practical basis for sports public service system. In this paper, we examine the status quo of the sports public service of Suzhou and the surrounding areas. Considering the situation of Suzhou, it is very important to explore how to construct sports public service system with Suzhou characteristic. The research methods we used include literature reviews, questionnaires and interviews, etc.

\section{Research Object and Research Methodology}

\subsection{Research Object}

We collect samples from 55 towns, 1068 administrative districts and 928 communities in Suzhou. We analyze the different elements of sports activities, sports facilities, sports guide and performance evaluation.

\subsection{Research Methodology}

\subsubsection{Literature Review}

We access to a large number of domestic and foreign literature through the network and library database. We look up Jiangsu Statistical Yearbook and some policy documents, laws and regulations of Jiangsu as well as Suzhou about sports public service. What's more, we processed and sorted these data, provided a solid theoretical basis for this paper.

\subsubsection{Interviews}

We interviewed the staff of Suzhou sports bureau, and the experts who participated in sports development programs, so we realized the current condition of Suzhou sports public service.

\subsubsection{Questionnaire}

We analyzed the situation of urban sports public service, combined and revised general scale of satisfaction at home and abroad, so that we made the original questionnaire. At first, we used the original questionnaire for small size of sample. According to the feedback, we revised the items and language expression again and finally finished "questionnaire of satisfaction of Suzhou sports public service".

The questionnaire contents were divided into two parts: the first is the basic information of the interviewees, including education, gender, income, etc. The second part is principal, namely the evaluation standard of satisfaction. And then, we sent the questionnaire randomly and collected data. We set 18 multiple-choices questions, using cumulative method of Likert scale which vary from one to five coded as very dissatisfied, dissatisfied, uncertain, satisfied, and very satisfied. We sent the questionnaires in public stadiums, sports academies, fitness center and other places. Then, we selected the effective questionnaire, saved the qualified data.

\section{Sports Public Service System}

The concept of public service as a new academic word which has been widely used but not strictly defined [3]. Sports public service is an important part of the public services provided by the government, which is one important function of modern government. Sports public service belongs to public service which the difference is the concept of sports public service narrower than public service.

Sports public service mainly refers to the public goods and services provided by public sectors, satisfy social member's basic demand of sports, provide sports culture enjoyment, and protect the survival and the development of society. That means besides the basic characters of public goods, namely non-competitive and non-exclu- 
sive, it has the following characteristics: Firstly, equality. Sports public service should be served equally, sports public facilities and public resources should be equal distribution, try to make sure everyone could enjoy the sports service. Secondly, it should be non-profits. Sports public goods and service offered by government should be non-profit. The purpose is pursuing the social benefits which make whole citizens enjoy the achievement of sports. Thirdly, it provides diverse choices. Sports public services and product should be diversity and multilevels, to satisfy different demands. The government should provide more varieties of sports services and products. Fourthly, it should be convenient. The Sports public service provided by the government should be close to residential district and used regularly, so that people can easily get anywhere. Fifthly, it could be popularization. Sports public service provided by government should be open to the public, all the residents can access to them [4].

The government is the main body for providing the sports public service which is determined by its nature. Providing the sports public service is the responsibility and obligation of government and it is also an important part of government's public service system. Perfecting the sports public service system enables to promote social harmony and improve the fitness environment. It can promote the comprehensive and sustainable development of society. Thus, improving sports public service could enhance the sports service function of government, enhancing the quality of sports public service, to achieve the need to maximize the service supply performance.

In modern market economy, government, the private sector, the third sector and community are all providers of sports public products, but the government is still the principal. In the new phase, sports public service system could satisfy diverse demand, and has important social function, also favor of social harmony and sustainable development.

\section{The Status Quo and Problems of Suzhou Sports Public Service System}

Sports public service system led by government, including various non-profit sports organizations and sports services to meet people's sport needs, protect the right of exercising, has the following aspects: Sports facilities, sports activities, and sports instructors, etc.

\subsection{The Status Quo of Suzhou Sports Public Service System}

\subsubsection{The Situation of Public Sports Facilities}

Now, the urban and county-level cities have built comprehensive sports center and stadium, and open to the public with low price or charge free. City sports center, Yunhe Sports Park and other major facilities are being constructed. The projects encompass a total of 160,000 square meters of building area. The project planning of sports center in industrial district has been completed, the construction space up to 420,000 square meters. 55 towns of the city built hobby centers, 1068 administrative villages finished sports and fitness program for rural residents, facilities covered urban and rural. In addition, Suzhou strive to build the " 10 minutes physical fitness circle" that combine the city and countryside, as of 2012, the "fitness circle" completed nearly $90 \%$ among all districts, Gusu district has the highest completion rate, is $100 \%$. Besides the e-map of " 10 minutes physical fitness circle" was online already, people can scan all kinds of facilities information more than 12,000 pieces. Besides, since 2010, Suzhou has called for volunteers to watch and maintain the equipment.

\subsubsection{Physical Activity and Resident Participation}

Suzhou gradually formed a series of brand events, such as "class for fitness collection" and so on. The physical activities can be divided into two categories, namely modern sports activities and traditional sports activities. To 2011, the residents participated in two types of activities for 4087 times, number of activities for 9.7 million people, which number of modern sports activities for 2400 times, totally 8.5 million people, number of traditional sports activities for 1687 times, totally 1.19 million people. The city-level districts held folk traditional sports activities and modern sports activities are 447 and 45 times, but the number of people who participated in the two kinds of activities is 310,000 and 6,010,000 respectively. The country-level districts held folk traditional sports activities and modern sports activities are 1240 and 2355. The number of people who participated in the two kinds of activities is 880,000 and 2,490,000. The data shows that folk traditional sports activities held more than modern sports activities, but the scale and the players are less than modern sports activities. The activities held by country-level districts are more than city-level districts, but the players are less than city’s. That means 
the level of the activities and the conscious of people to participate activities have big difference between citylevel and country-level districts.

\subsubsection{Sports Instructor and Sports Associations}

Statistical data shows that as of 2012, the number of sports instructor is 21,670, of which national-level sports instructor for 91, the provincial level, provincial secondary and tertiary instructors are respectively 577, 6164 and 14,838. Zhangjiagang and Changshu have more national instructors, the number of which is 17 and 10 respectively, the number of provincial level instructors more than 100 people, up to 190 and 113 respectively. Kunshan has the largest number of instructors, up to 4960 people. Compared with the total population, the registered people have 33.45 instructors per ten thousand people, and the resident have 20.75 instructors per ten thousand people. The total number of registered sports clubs and associations is 156, which 31 city associations, 28 city clubs. The number of associations and clubs in many districts more than a dozen, Wujiang has the most, up to 20 . To the end of 2012, the total number of clubs and associations add up to 556,346, of which city association's members is 74,325 , city club's member is 54,510 . The data shows that the number of clubs and associations is large, and in recent two years, the number increased quickly.

\subsection{The Problems of Suzhou Sports Public Service System}

\subsubsection{The Average Number of Participation in Sports Activities Is Not Much}

From the data we surveyed, the number of two kinds activities that resident participated is 4087, of which the number of modern sports activities is 2400 , the number of resident who participated is more than 8 million and the number of folk sports activities is 1687, the number of resident who participated is more than 1 million. Compare with the registered population and regular residence population, our survey figures that each registered person participates in sports activities 1.5 times per year, each permanent resident person even less than one time. The average level is low. This is because the person has weak fitness awareness, also maybe because the sports public facilities is insufficient, result in people can't participate in sports activities.

\subsubsection{Lack of Professional Sports Instructors}

From the survey, except Zhangjiagang and Changshu, the number of national instructors in the rest districts less than 10 people, the number of provincial level instructors less than 100. Compare our statistical data with total population can be seen that registered population have 33.45 sports instructors per ten thousand people, regular residence have 20.71 sports instructors per ten thousand people. There is still a big difference among different districts on the instructor's number of per ten thousand people. In Kunshan district, per ten thousand registered people have 67.21 instructors, the highest ratio in Suzhou. But the number of instructors that per ten thousand resident have is not the most. It means that this district has large floating population. Huqiu has the lowest ratio of the number of instructors that per ten thousand registered people have, which is 5.28 people. Too few sports instructors resulting low guidance rate for exercise, lead to residents can't exercise scientifically.

\subsubsection{The Number of Clubs and Membership Is Small}

Similarly, there is a large difference among the total number of associations and clubs in different districts. Wujiang has the most clubs, up to 20. Xiangcheng and Jinchang have the least club, only one. Also the number of registered membership still have large gap among different districts. The number varies from 100 to nearly 4000, which shows the unbalance of club development. The statistics we surveyed about the number of clubs and membership compared with the total population shows that every 40 thousand people have one sports club among registered people; every 60 thousand people have one sports club among regular residence. Obviously, the number of sports associations is too small, and compared to the population of the city, number of clubs members is not much either.

\subsubsection{There Is a Large Gap between Urban and Rural Sports Public Services}

According to the analysis of the current situation, we find that the number of county-level people who participated in sports activities is significantly lower than city residents. Statistical analysis can be seen from the data above, there are significant differences among different districts about the sports service and sports facilities, such as the underdeveloped regions lagging behind the developed regions, the urban region developed better 
than countryside. As the modern sports, the proportion of country residents who participated is still lower than urban residents. Besides, according to the national monitoring station, the fitness compliance rate of rural area people is worse than the urban people. These are fully explained, there is a big difference between urban and rural sports public services.

\section{Countermeasures for Suzhou Sports Public Service System}

\subsection{Define Government Responsibility, Reinforce the System of Government}

The government- the body responsible for sports public service system, should undertake the burden of construction and improvement of it, such as allocated sports resources, scientific decision-making, etc. the government should develop a series of laws and regulations to protect the supply of sports public service, explore sports-related special regulations and regulate sports service market, so that we could construct the legal environment of sports public service to establish the sports public service system [5]. Suzhou should combine with its own advantages and city features, to develop laws and regulations according to the requirement of sports development plan of Jiangsu province, and gradually promote the equalization of sports public service, so that it can reflect the nature of sports public service, such as fairness, universality, etc.

\subsection{Improving the Sports Public Service Facilities}

Stadium construction should be practical, effective and scientific; also it should be diverse with multi-functions. Based on the social economy level, environment and demands for sports, the government plans public sports units, the number of sports facilities and categories, to improve the quality of public sports goods and service [6]. What's more, the government fully utilizes and integrates sports resources, open all the stadiums to the public gradually, improving the people's exercising conditions. Let people enjoy exercising, which bring people fitness and happiness. Besides, Suzhou should construct brand sports activities and classic sport project, hold more diverse sports activities. It should increase development efficiency of nature resources, keep holding traditional sports activities, enrich people's exercise choices.

\subsection{Develop the Third Departments and Broaden the Supply Channel of Sports Public Service}

In general, governments are more suitable for providing relatively high homogeneity sports public service, but the third departments have great advantages of providing heterogeneous products [7]. Suzhou should increase financial investment in sports public development, bring sports public service items into the special financial budget, providing financial support for construction of sports public service system. In addition, the government should further broaden the supply channels of public sports services, encourage the social capital into public sports products and services and put efforts to solve dismal infrastructure problems. Combing government funding and social forces, the government should authorize certain non-profit sports organization to serve the public, so that they can broaden the supply channels of public service to increase supply of sports public service. Suzhou would build more stadiums to meet the diverse needs as well as shorten the gap between urban and rural places of sports development.

\subsection{Establish the Performance Evaluation System of Sports Public Service}

In performance evaluation of public service, the quality services and satisfaction of the public is the first evaluation criteria, the government can't pursue economic indicators only, but also consider the comprehensive index [8]. Performance evaluation plays an important role to impact the work quality and style. Establishing a set of scientific standards of sports public service system could be used to assess the basic situation of the system effectively and objectively. So that it's helpful to reconfigure and reallocate the resource of public service, support and protect the development of economy and society. In addition, the government can transfer to service-oriented, making people's benefit first, to achieve the equalization of sports public service. So that establishing the performance evaluation system of public service is an effective way to regulate government behavior and improve the efficiency of public service. 


\section{Conclusions}

Now, the sport public service system of Suzhou is gradually being formed, stadiums and clubs are increasing more and more, residents have more choices to participate in sports activities. But beyond that, there is still a great gap between regions. Also, because of unbalanced regional development and lacking of exercise awareness, the average level of exercising is not high. To realize the equalization of sports public service, it is required that different regions develop harmoniously, broaden the supply channel of the third department, and enhance the system protection of the government.

In addition, our study has important significance. First, we examine the construction situation of Suzhou sports public service system and understand sports public service field in depth. Meanwhile, some other places could learn from Suzhou to develop sports public service. The development experience of Suzhou could be used in other regions and even can be raised to guidelines. Second, we adopt new public service theory as the basis of our research which is a new theory in public administration field. Our results examine and support the theory and also we put this theory into practice which enriches the study of the theory. Finally, we see the issue of government transformation from the service-oriented and sports public view, which provide new sight for the government function transformation. It could help the government focus people's needs, transfer government function and make service oriented.

\section{References}

[1] Miao, C.Z., Hu, P., et al. (2012) Construct Background and Conceive of Public Athletics Service System in Heilongjiang. Journal of Harbin Institute of Physical Education, 4, 38-41.

[2] Liu M.S. and Li, J.G. (2010) Construction of a Sports of Public Service System from the Angle of New Public Service Theory. Sports Science Research, 4, 54-56.

[3] Huan, C.D., Xiao, L.P., et al. (2009) Framework of Public Sport Service in China. Journal of Shandong Institute of Physical Education and Sports, 2, 4-9.

[4] Jing, L. and Rong, C. (2009) Status Quo of and Countermeasures for the Public Service System of Zhejiang Community Sports-Taking Hangzhou as an Example. Journal of Chengdu Sport University, 12, 23-25.

[5] Zhou, A.G. (2012) Discussion on Government Position and Function from the Perspective of Sports Public Service Concept. China Sports Science, 5, 64-70.

[6] Jing, L. (2009) Study on Sports Public Service System. Journal of Nanjing Institute of Physical Education, 2, 62-65.

[7] Xiao, L.P., Li, Z.H., et al. (2007) On the Conception and Theories of Public Sports Service. Journal of TUS, 2, 97-101.

[8] Wang, C.X. (2008) Establishing a Perfect Sports Public Service System. Sports Science Research, 2, 1-13. 
Scientific Research Publishing (SCIRP) is one of the largest Open Access journal publishers. It is currently publishing more than 200 open access, online, peer-reviewed journals covering a wide range of academic disciplines. SCIRP serves the worldwide academic communities and contributes to the progress and application of science with its publication.

Other selected journals from SCIRP are listed as below. Submit your manuscript to us via either submit@scirp.org or Online Submission Portal.
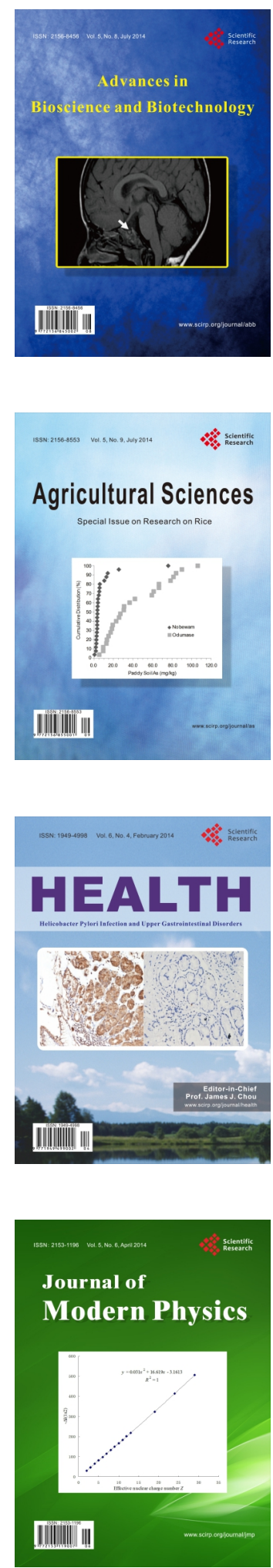
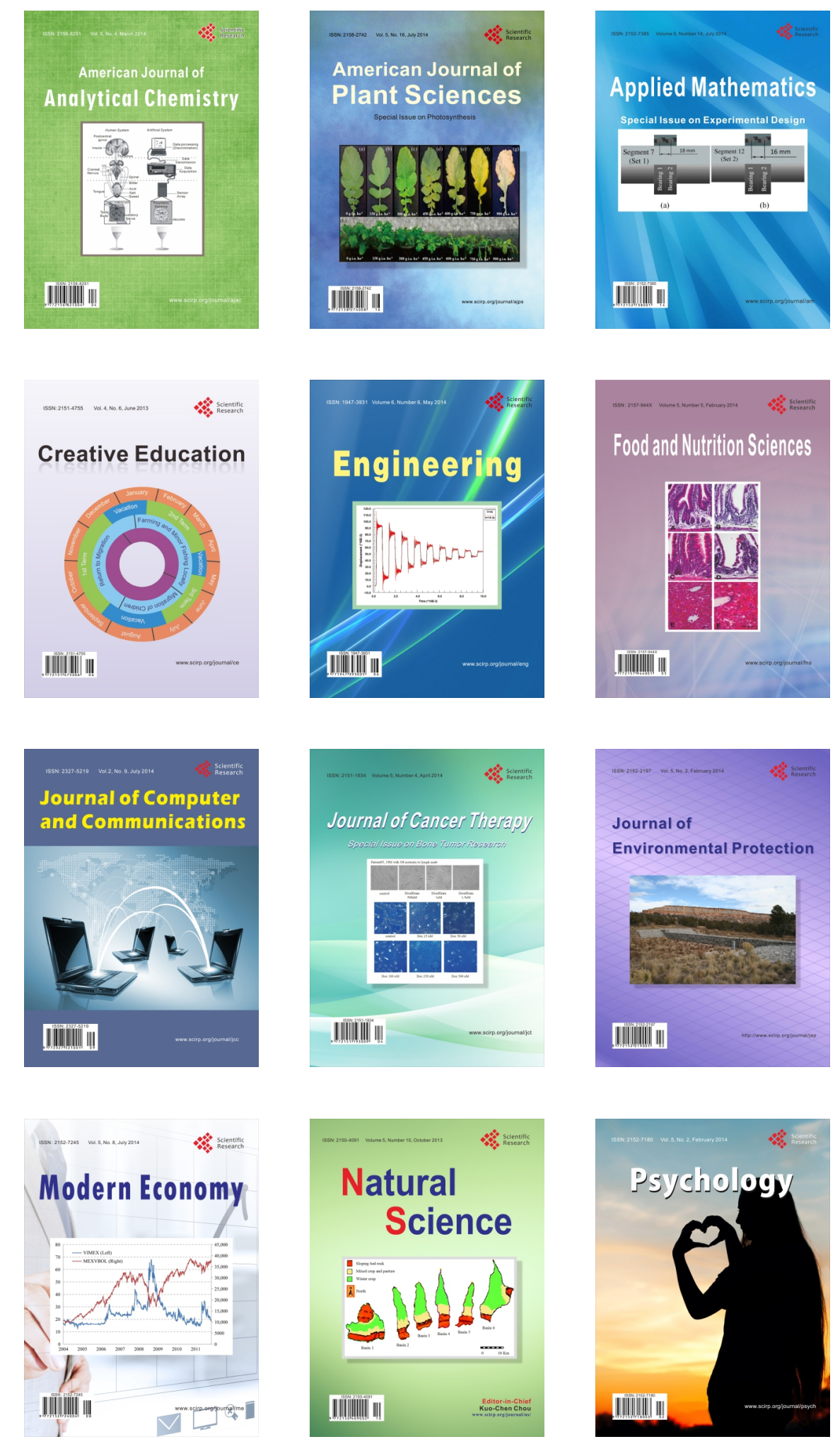